\title{
Energy Consumption of an Electrified Light Duty Vehicle by considering the Link Voltage's Variation
}

\author{
Anna-Lena Menn ${ }^{1}$, Florian Mittelstädt ${ }^{1}$, Markus Henke ${ }^{1}$ \\ ${ }^{1}$ Institute of Electrical Machines, Tractions and Drives, Technical University Braunschweig, Germany \\ Hans-Sommer-Str.66, 38106 Braunschweig,a-l.menn@tu-bs.de
}

\begin{abstract}
The present paper outlines an analysis of the energy consumption of a light commercial vehicle that is powered purely electrically by an induction machine. The question was to what extent energy consumption is impacted by two defined aspects: On the one hand these are different control concepts for the traction machine and on the other hand varying link voltage. At first the influence of the controls on the energy consumption of the drive unit will be analyzed, followed by an efficiency analysis that takes into account the different controls at varying link voltage.
\end{abstract}

Keywords: Asynchronous (induction) motor, BEV, Controller, Efficiency, Energy consumption

\section{Introduction}

Today's battery electric vehicles are mostly powered by a permanent magnet synchronous machine because it boasts excellent efficiency rates and a compact design. On the downside, there is the need for rare earth materials that are available only in limited supply and thus prone to entailing high manufacturing costs. This is why in the following we will focus on an induction machine as a vehicle drive. It has a smaller overall efficiency which, however, can be increased by optimum efficiency controls [1].

The $40 \mathrm{~kW}$ induction machine employed was laid out as a vehicle drive [1] whose control was tailored to optimum efficiency in two different ways and which serves as drive of a light commercial vehicle. The latter is represented as a Simulink model comprising all related components in view of the tests to be performed. At first our contribution focuses on the effect of the controls on the efficiency of machine and power electronics before detailing the effects of varying link voltages on the efficiency.

\section{Modular Simulation Structure}

Our research is based on a quasi-stationary forward simulation of a light commercial vehicle. Fig.1 displays the vehicle topology employed and the related components. The simulation model is made up modularly so that the individual components can be exchanged if need be.

\subsection{Vehicle Topology and Model Components}

The concept in question is that of a light commercial vehicle whose power source is a battery and which is driven by an induction machine (IM) at the front wheel. It comprises exclusively a differential gear ( $i_{\text {diff }}$ ) for converting the torque and the rpm. The vehicle data applied are listed in Table 1.

The driver aims to abide by a predefined speed; therefore the driver model is laid out as a PI controller and transmits the torque demand to the drivetrain. 

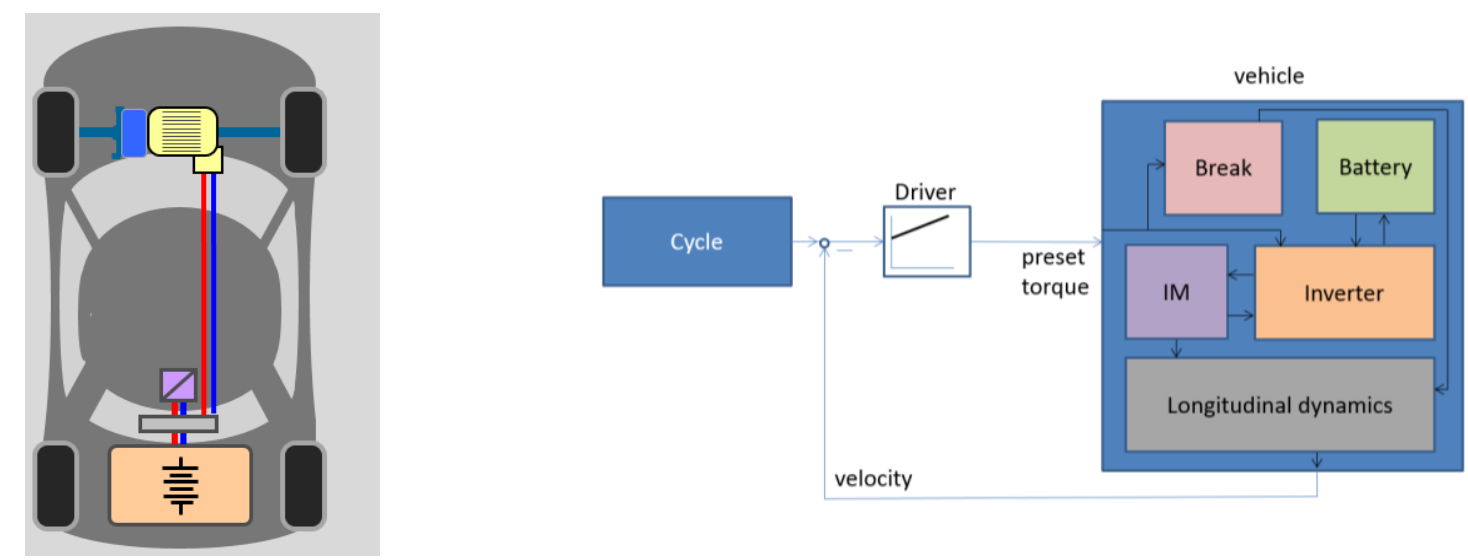

Figure 1: Drive topology employed and structure of the vehicle model

In the „longitudinal dynamics“ block the driving resistances are computed that a vehicle has to overcome before starting to move. Also the wheel power of the induction machine that is available for overcoming these driving resistances is $F_{\text {resistance }}$ computed. The thrust is as follows:

$$
F_{\text {thrust }}=M_{I M} * \frac{i_{\text {diff }}}{r_{\text {wheel }}}
$$

The equation

$$
\Delta F=F_{\text {thrust }}-F_{\text {resistance }}=m * a
$$

describes an acceleration (a) that the vehicle is able to achieve. Integration yields the actual velocity that is transmitted to the driver module for determining the actuating variable $\left(\mathrm{M}_{\mathrm{IM}}\right)$.

In the battery model, the battery voltage is determined according to Equation (3) [7]. It is also required in the model of the inverter for voltage limitation as well as for computing the inverter losses and the battery power. For this purpose, the battery current $I_{b a t}$ necessary for the equation is determined in the inverter module subject to the respective load situation.

$U_{\text {bat }}=n_{\text {cell }} *\left(U_{0}-R_{i} * I_{\text {bat,string }}-A * \frac{1}{\operatorname{SOC}(t)} * I_{\text {bat,string }}-B * I_{\text {bat,string }}\right)$

The process uses a Li-ion battery with the parameters listed in Table 2. Moreover, the model comprises two different battery configurations having the open circuit voltages $\mathrm{U}_{0} 280 \mathrm{~V}$ and $350 \mathrm{~V}$, respectively.

The braking torque is computed by means of a serial strategy that depends on the deceleration demanded by the driver. In case of small decelerations at first only an electric regenerative braking is applied; with higher deceleration values, additionally the mechanical friction brake is put into effect. The braking torque is transmitted to the longitudinal dynamics module.

The model of the electric machine consists of a dynamic field oriented $d, q$-model which makes sure that the transition between two operating points will be represented precisely [4]. According to the control voltages transmitted by the inverter and on demand by the driver, the machine model generates a reference torque for the model of the longitudinal dynamics so that, according to Equation (2), a desired acceleration resp. speed can be maintained. Moreover, the machine model transmits the rotor flux $\Psi_{R}$ and the (independent) current components $i_{s d}, i_{s q}$ to the inverter model for machine control. For determining the dynamic efficiency, the machine losses, i.e., stator-, rotor-, and iron losses, are computed in this model. The information necessary for modeling the induction machine will be detailed in Chapter 3. For a traction machine we use an induction machine using the parameters listed in Table 1.

In the inverter model the machine control and the power loss computation of the inverter are implemented. The inverter is a fully active B6 bridge described by the characteristics in Table 1 . The machine control computes the required control voltages for the machine which will be realized by the inverter by means of pulse width modulation; thus it will be possible to generate a reference torque demanded by the driver. 
Table 1: Vehicle component data

\begin{tabular}{|c|c|c|c|}
\hline \multicolumn{2}{|l|}{ Induction machine } & \multicolumn{2}{|l|}{ Vehicle data } \\
\hline Nominal power & $39 \mathrm{~kW}$ & Vehicle mass & $1447 \mathrm{~kg}$ \\
\hline Maximum power & $90 \mathrm{~kW}$ & Wheel diameter & $0.34 \mathrm{~m}$ \\
\hline Nominal speed & $50001 / \mathrm{min}$ & Vehicle height & $1.79 \mathrm{~m}$ \\
\hline Maximum speed & $150001 / \mathrm{min}$ & Differential-gear ratio & 9.5 \\
\hline Number of pole pairs & 3 & Total brake torque & $1,200 \mathrm{Nm}$ \\
\hline \multicolumn{2}{|c|}{ Inverter SEMIX453GB12E4s } & \multicolumn{2}{|l|}{ Battery cell } \\
\hline Switch frequency & $10 \mathrm{kHz}$ & Open circuit voltage & $3,426 \mathrm{~V}$ \\
\hline Power factor & 1 & Internal resistance & $0,008 \Omega$ \\
\hline Modulation depth & 0.9 & Battery stack & \\
\hline \multirow[t]{2}{*}{ Nominal voltage } & $600 \mathrm{~V}$ & Configuration 1: $280 \mathrm{~V}$ & $101 \mathrm{~s} 5 \mathrm{p}$ \\
\hline & & Configuration 2: $350 \mathrm{~V}$ & $82 \mathrm{~s} 5 \mathrm{p}$ \\
\hline
\end{tabular}

\section{Machine Modeling and Control Method}

\subsection{Machine Model}

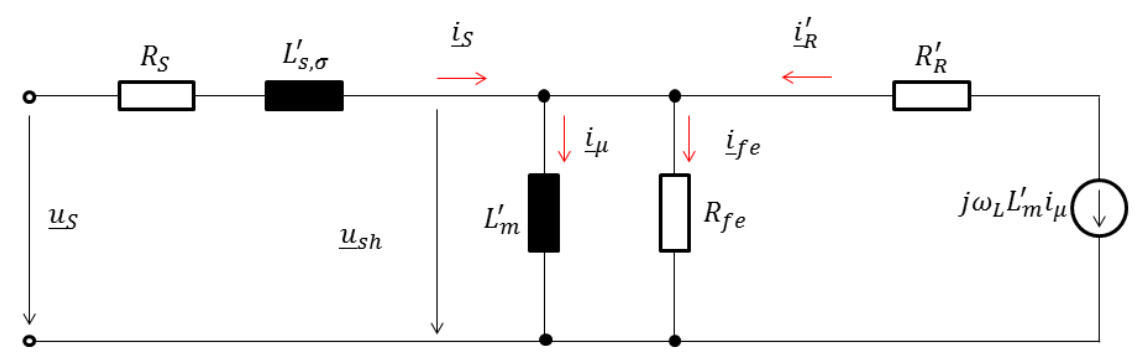

Figure 2: Equivalent circuit diagram rotor flux oriented coordinate system

Modeling of the induction machine is based on the equivalent circuit diagram in Fig. 2 in the rotor flux oriented coordinate system with the definition $\Psi_{R}=i_{\mu} * L_{m}$, with $\omega_{m R}$, the electric angular velocity of the rotor flux, and $\omega_{R}$, the electric angular velocity of the rotor. The resulting system equations represented by space vectors are the following:

$\underline{u}_{s}=R_{s} * \underline{i}_{s}+L_{s, \sigma}^{\prime} \frac{d}{d t} \underline{i}_{s}+\mathrm{j} * \omega_{m R} * L_{s, \sigma}^{\prime} * \underline{i}_{s}+L_{m}^{\prime} *\left(\frac{d}{d t} \underline{i}_{\mu}+j * \omega_{m R} * \underline{i}_{\mu}\right)$

$\underline{i}_{s}=\underline{i}_{\mu}+\underline{i}_{f e}-\underline{i}_{R}^{\prime}=\underline{i}_{\mu}+\frac{L_{m}^{\prime}}{R_{c}} *\left(j \omega_{m R} * \underline{i}_{\mu}+\frac{d}{d t} \underline{i}_{\mu}\right)+\frac{L_{m}^{\prime}}{R_{R}^{\prime}} *\left(\frac{d}{d t} \underline{i}_{\mu}+j\left(\omega_{m R}-\omega_{R}\right) \underline{i}_{-\mu}\right)$

with

$L_{s, \sigma}^{\prime}=\sigma * L_{s}=\frac{L_{s} * L_{R}-L_{m}^{2}}{L_{R}}, L_{m}^{\prime}=(1-\sigma) * L_{s}=\frac{L_{m}^{2}}{L_{R}}, R_{R}^{\prime}=\left(\frac{L_{m}}{L_{R}}\right)^{2} * R_{R}$

If the space vectors are described in the $d, q$ representation as

$$
\underline{u}_{s}=u_{s d}+j u_{s q}
$$




$$
\begin{aligned}
& \underline{i}_{s}=i_{s d}+j i_{s q} \\
& \underline{i}_{\mu}=i_{\mu d}+j i_{\mu q}=i_{\mu d}=i_{\mu}
\end{aligned}
$$

this will yield, subsequent to a division into real and imaginary parts, the equations for voltage and current:

$$
\begin{gathered}
u_{s d}=R_{s} * i_{s d}+L_{s, \sigma}^{\prime} \frac{d}{d t} i_{s d}-\omega_{m R} * L_{s, \sigma}^{\prime} * i_{s q}+L_{m}^{\prime} * \frac{d}{d t} i_{\mu} \\
u_{s q}=R_{s} * i_{s q}+L_{s, \sigma}^{\prime} \frac{d}{d t} i_{s q}+\omega_{m R} * L_{s, \sigma}^{\prime} * i_{s d}+\omega_{m R} * L_{m}^{\prime} * i_{\mu} \\
i_{s d}=i_{\mu}+\left(\frac{L_{m}^{\prime}}{R_{c}}+\frac{L_{m}^{\prime}}{R_{R}^{\prime}}\right) * \frac{d}{d t} i_{\mu} \\
i_{s q}=\frac{L_{m}^{\prime}}{R_{c}} \omega_{m R} * i_{\mu}+\frac{L_{m}^{\prime}}{R_{R}^{\prime}}\left(\omega_{m R}-\omega_{R}\right) i_{\mu} \\
i_{\mu}=\frac{\Psi_{R}}{L_{m}}
\end{gathered}
$$

In the coordinate system oriented according to the rotor flux, the torque provided by the induction machine is:

$$
M_{e l}=\frac{m_{s}}{2} p \frac{L_{m}^{2}}{L_{R}} i_{\mu} i_{s q}=\frac{m_{s}}{2} p \frac{L_{m}}{L_{R}} \Psi_{R} i_{s q}
$$

\subsection{The Control Methods Employed}

Subsequent to the modeling of the induction machine in the rotor flux oriented coordinate system two control methods, functioning in different ways, will be presented in view of increasing the efficiency of the induction machine. In both cases an optimum reference flux is computed; it brings about an increased efficiency of the traction machine.

As displayed in Fig. 4, these control methods are integrated in the field oriented control (FOC) by means of the block $\psi_{\text {opt }}$ in which the optimum flow is computed. In order to ensure an efficiency optimal operation also in the field weakening area, here the conventional structure of field weakening is used in the shape of a voltage limitation in addition to the $\psi_{\text {opt }}$ block [5]. This precludes setting too high a flux in the field weakening area.

Thus the reference value transmitted to the flux controller is:

$$
\Psi_{R, \text { soll }}=\min \left(\Psi_{R, o p t} ; \Psi_{R, F S B}\right)
$$

Here the effectivity of loss minimization depends on the exact computation of the machine parameters, e.g., of resistances and inductivity [3].

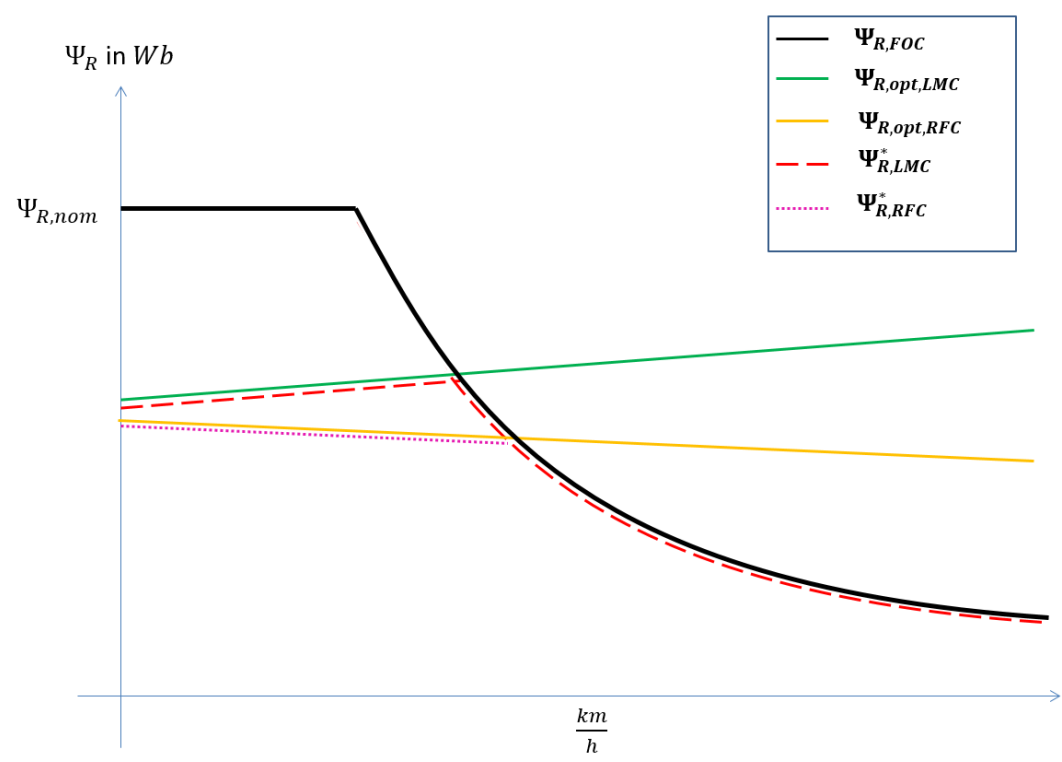

Figure 3: Flux curves for the three controls 


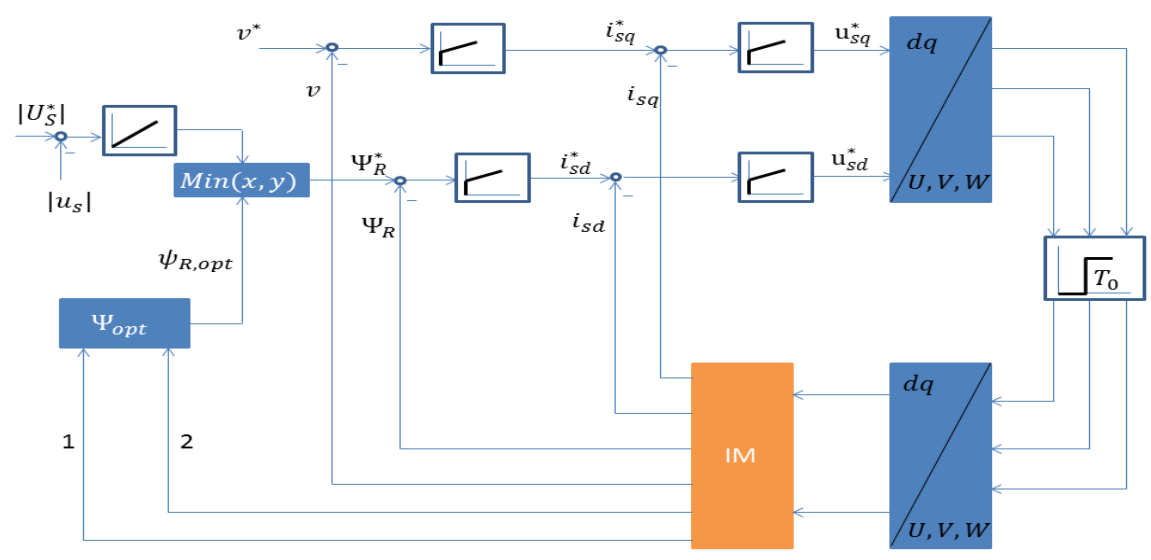

Figure 4: Scheme of control strategy of the induction machine

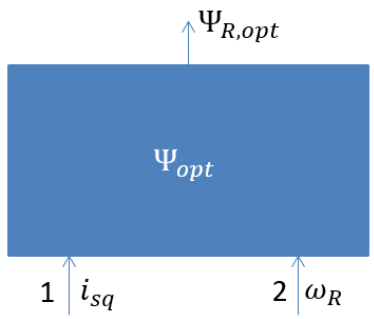

Figure 5: Integration of LMC in FOC

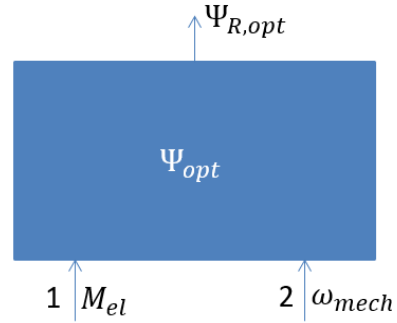

Figure 6: Integration of RFC in FOC

\subsection{Loss model-based Controller (LMC)}

With the loss model-based controller (LMC) the losses are computed by means of a substitute diagram of the induction machine in field coordinates displayed in Fig. 2 (Chapter 3.1) and minimized by setting an optimum flux rate.

For developing the LMC one takes into account the model equations (Chapter 3.1) in the stationary state. Only the losses that [2] proclaims to be crucial are taken into account, with the iron losses being related to the stator:

$$
P_{\text {Loss }}=P_{\text {stator }}+P_{\text {iron }}+P_{\text {rotor }}
$$

Inclusion of the modeling equations into the stationary state yields the equation:

$$
P_{\text {Loss }}=R_{S} *\left(i_{s d}^{2}+i_{s q}^{2}\right)+R_{c} *\left(i_{s q}-i_{R}\right)^{2}+R_{R}^{\prime} * i_{R}^{2}
$$

As in this equation only the currents $i_{s d}$ and $i_{s q}$ represent state variables, the loss equation with

$$
i_{R}=i_{s q}-i_{f e}=i_{s q} \frac{R_{c}}{R_{c}+R_{R}^{\prime}}+i_{s d} \frac{L_{m}^{\prime}}{R_{c}+R_{R}^{\prime}} * \omega_{R}
$$

is expressed only by $i_{s d}$ and $i_{s q}$ :

$$
\begin{gathered}
P_{\text {Loss }}=R_{d} * i_{s d}^{2}+R_{q} * i_{s q}^{2} \\
\text { with } R_{d}=R_{S}+\frac{L_{m}^{\prime} * \omega_{R}^{2}}{R_{c}+R_{R}^{\prime}} \text { and } R_{q}=R_{S}+\frac{R_{c} * R_{R}^{\prime}}{R_{c}+R_{R}^{\prime}}
\end{gathered}
$$

As an optimum flow value is to be provided by means of LMC and because $i_{s d}=i_{\mu}$ is valid in the stationary state, the determined loss equation is minimized in correlation with $i_{s d}$ : 


$$
\frac{d P_{\text {Loss }}}{d i_{s d}}=2 * R_{d}\left(\omega_{R}\right) * i_{s d}+R_{q} * \frac{d}{d i_{s d}} i_{s q}=0
$$

Application of the torque equation (Chapter 3.1) enables the following differentiation:

$\frac{d P_{\text {Loss }}}{d i_{s d}}=2 * R_{d}\left(\omega_{R}\right) * i_{s d}+R_{q} *\left(\frac{M_{e l}}{\frac{m_{s}}{2} * p * \frac{L_{m}^{2}}{L_{R}}}\right)^{2} \frac{d}{d i_{s d}} \frac{1}{i_{s d}^{2}}=2 * R_{d}\left(\omega_{R}\right) * i_{s d}-R_{q} * 2 * \frac{i_{s q}^{2}}{i_{s d}}=0$

With $\Psi_{R}=i_{\mu} * L_{m}$ this yields the final equation:

$$
\Psi_{R, o p t}=i_{\mu, o p t} * L_{m}=L_{m} * \sqrt{\frac{R_{q}}{R_{d}\left(\omega_{R}\right)}} * i_{s q}
$$

This equation represents the algorithm that in real time minimizes the above mentioned losses as compared with the field oriented control. In the following display (Figure 5) the algorithm is included into the field oriented control of Figure 4 . The components $i_{s q}$ and $\omega_{r}$ required for the algorithm can be taken from the model of the induction machine.

Figure 3 displays the qualitative magnetic flux curves of the field oriented control (thick,black) and of the LMC (green). It can be seen that the flux value of the LMC, due to a direct dependence on the torqueinducing current $i_{s q}$, exceeds that of the field oriented one at a certain speed/load. This is the case if a higher speed requires a stronger field weakening than that computed by LMC. For optimum operation of the induction machine in the field weakening area we select the procedure marked by the red broken line.

\subsection{Rotor Frequency Optimization Procedure}

In the procedure presented here, the optimum flux is computed by means of the corresponding optimum rotor frequency.

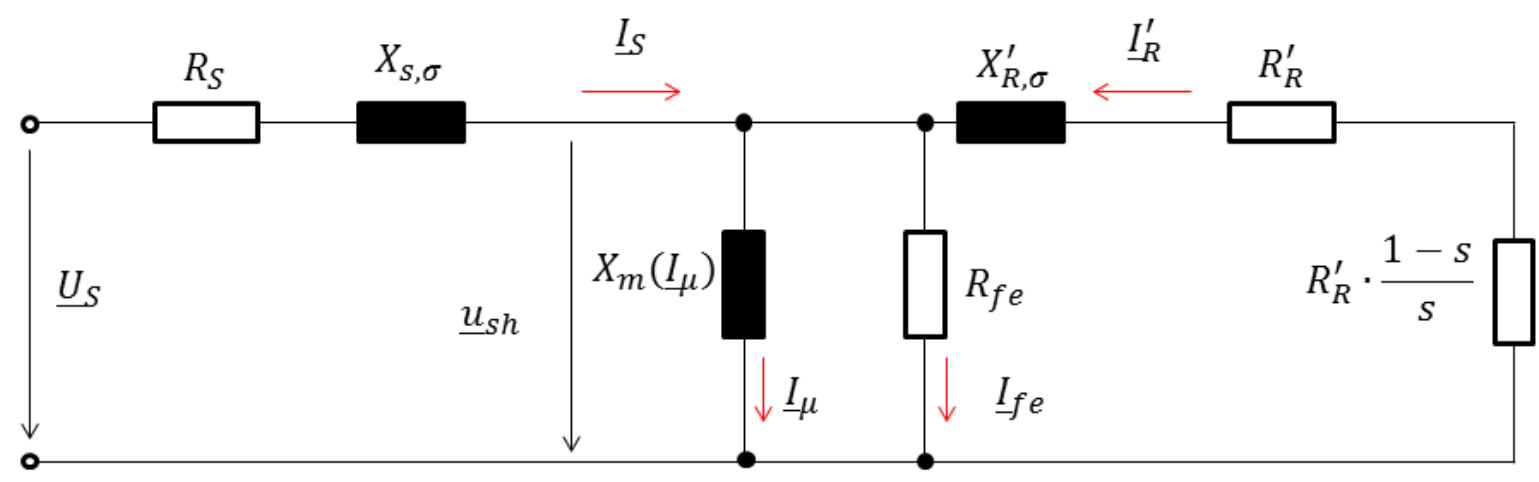

Figure 7: Equivalent circuit diagram for RFC

As regards the computation steps, the optimization procedure is oriented according to the equivalent circuit diagram in Fig. 6. For any desired point in the speed torque characteristic of the induction machine, at first the rotor frequency $\omega_{\mathrm{r}}$ and the slip $s$ are determined by means of the reference rotor flux according to the following equations.

$$
\begin{aligned}
& \omega_{\mathrm{r}}=\frac{\mathrm{M} *\left(\mathrm{~L}_{\mathrm{r}, \sigma}+\mathrm{L}_{\mathrm{sh}}\right)}{\mathrm{m}_{\mathrm{s}} * \mathrm{p} * \mathrm{~T}_{\mathrm{r}} * \Psi_{\mathrm{r}}^{2}} \\
& s=\frac{\omega_{\mathrm{r}}}{2 \pi p * \frac{n}{60}+\omega_{\mathrm{r}}}
\end{aligned}
$$

In a next step the powers and voltages are computed according to the equivalent circuit diagram (Fig. 6) for the constant torque and the field weakening areas. During computation in the latter, close attention must be paid to the voltage requirement. For checking if the machine is in the field weakening area, the stator voltage is determined and compared to a defined voltage limit $U_{S}^{*}$ :

$$
U_{s}^{*} \lessgtr\left|\underline{U}_{s}\right|=\left|\left(R_{s}+j * \omega_{s} * L_{s \sigma}\right) * \underline{I}_{S}+\underline{U}_{s h}\right|
$$

Then the efficiency $\eta$ is assessed, depending on the stator losses $\mathrm{P}_{\mathrm{V}, \mathrm{S}}$, those of the rotor $\mathrm{P}_{\mathrm{V}, \mathrm{R}}$, and the iron losses $\mathrm{P}_{\mathrm{V}, \mathrm{Fe}}$ : 


$$
\eta=\frac{P_{m e c h}}{P_{m e c h}+P_{V S}+P_{V R}+P_{V f e}}
$$

In the following the procedure is repeated at an increased rotor frequency with the same operating point until an optimum efficiency is identified. Eventually the rotor frequency $\omega_{R}$ yielding the maximum efficiency will be stored in a look-up table. This algorithm is then applied to all existing points in the characteristic diagram.

The look-up table is integrated into the field oriented control in Fig. 6. Moreover, within the $\psi_{\text {opt }}$ block the optimum rotor frequency is converted into the rotor flux according to the following equation

$$
\psi_{r}=\sqrt{\frac{\mathrm{M} *\left(\mathrm{~L}_{\mathrm{r}, \sigma}+\mathrm{L}_{\mathrm{sh}}\right)}{\mathrm{m}_{\mathrm{s}} * \mathrm{p} * \mathrm{~T}_{\mathrm{r}} * \omega_{\mathrm{r}}}}
$$

in such a way as to generate a reference value $\Psi_{R, o p t}$ for the flux controller.

\section{Analysis of Energy Consumption}

\subsection{Effects of the Control Strategies on the Losses}

\subsubsection{Effects on the Machine Losses}

In the following we will detail the effects that the control strategies described have on the losses under the assumption of an open circuit voltage of $350 \mathrm{~V}$. Firstly we will examine the machine losses, taking into account ohmic losses in stator and rotor, iron losses as well as switching and conducting losses of the inverter. The losses are measured at velocities that are typical of German traffic. Field oriented control serves as a reference.
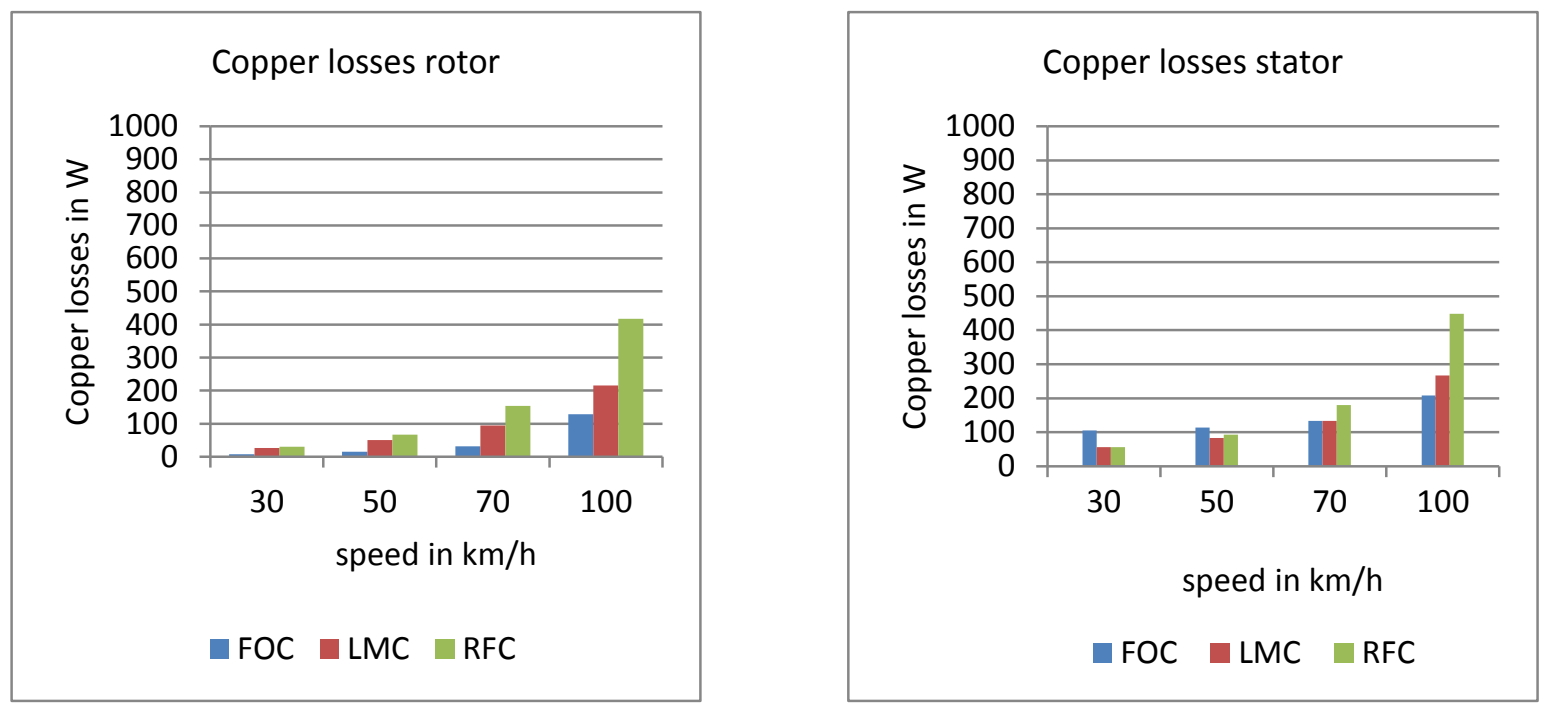

Figure 8: Copper losses in rotor and stator at $350 \mathrm{~V}$

The inevitable rise of stator losses with increasing speed can be attributed to the fact that with increasing driving resistances (in particular air resistance) the power requirement will also go up. What is more, at velocities of more than $70 \mathrm{~km} / \mathrm{h}$ the stator losses in either of the two minimization procedures exceed the losses in the field oriented control. This results from the control related flux minimization that brings about a larger demand for $I_{s, q}$, in which case the condition $P=$ const is again being complied with.

In the efficiency optimizing procedures, rotor losses will increase over the whole velocity range in question. This is due to the machine running continually under optimum rotor flux, to the effect that the rotor losses will increase. These observations have already been presented in [1] and [6]. 


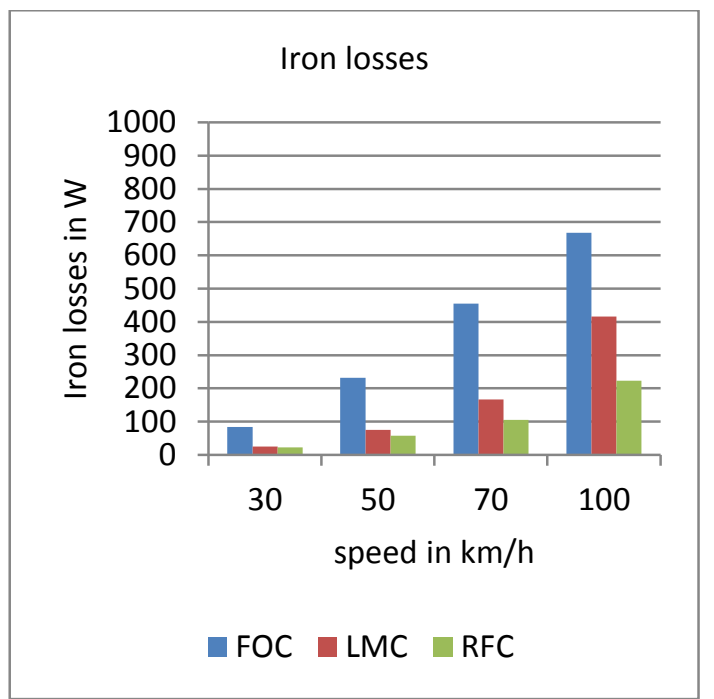

Figure 9: Iron losses at $350 \mathrm{~V}$

The largest proportion in the minimization falls to the iron losses in relation to the overall losses of the machine. In a direct comparison of LMC to FOC, a reduction of $69.4 \%$ is effected at $30 \mathrm{~km} / \mathrm{h}$ while at 100 $\mathrm{km} / \mathrm{h}$ it is still $55.3 \%$.

The reason for the drastic reduction is the linear correlation between the iron loss current and the magnetizing current (cf. Chapter 3, Equation 5). Due to an optimum flux in the area of constant torque (Fig.4) the iron losses can be reduced. The largest difference is revealed by a direct comparison between FOC and RFC. Its cause can also be seen clearly in Fig. (4). In the RFC, the optimum flux value is below that of the two other procedures.

The test results yield the efficiency curves for the electric machine under the three controls as displayed in the following. It is evident that the efficiency optimized procedures boast significantly higher efficiency rates than do the FOC. From a velocity of $90 \mathrm{~km} / \mathrm{h}$ on there is an approximation resp. an improved energy balance for the FOC (RFC in direct comparison to FOC). Over the whole velocity range the LMC is more efficient than the other two controls.

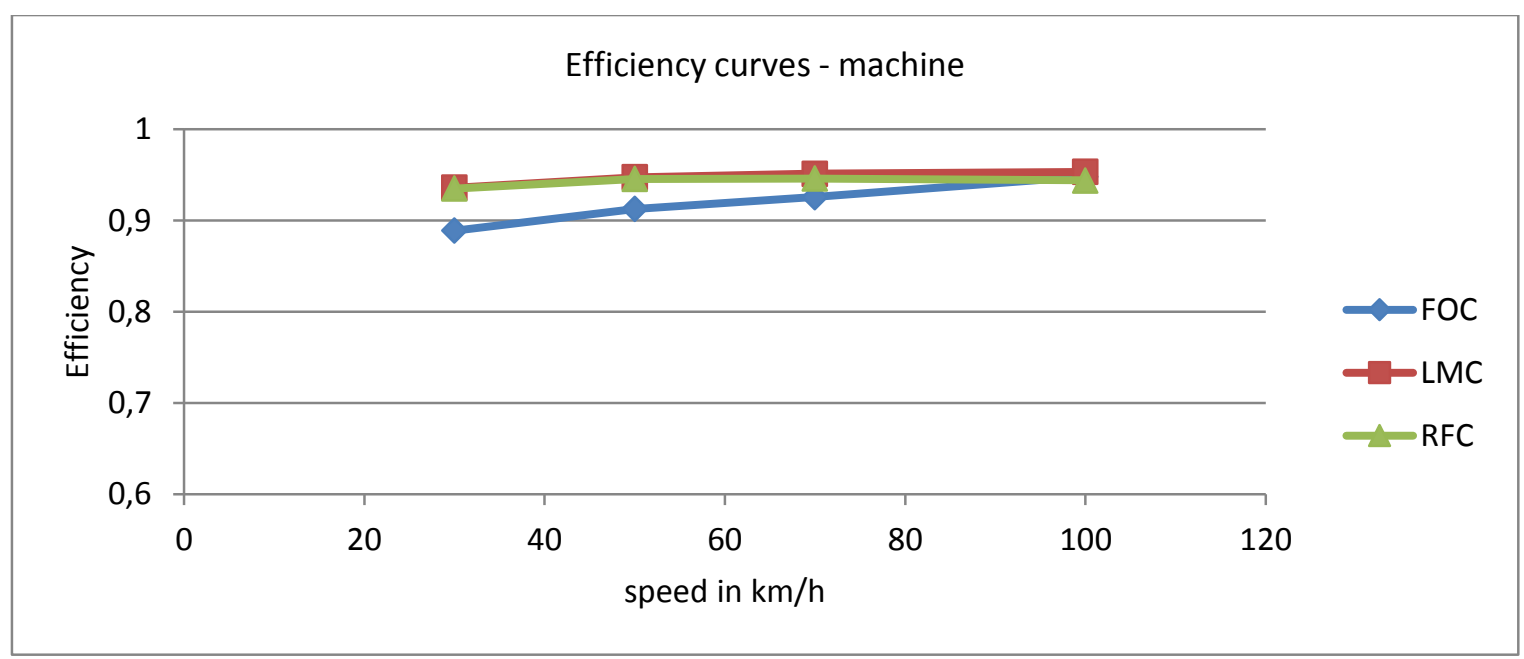

Figure 10: Efficiency curves - machine at $350 \mathrm{~V}$

\subsubsection{Effects on the Inverter Losses}

Considering now also the switching and conducting losses in the power electronics, one clearly sees that the maps describing the losses correspond to those of the stator losses. This is a result of the two inverter losses being proportional to the stator current. Up to velocities of $50 \mathrm{~km} / \mathrm{h}$ they are smaller than with the FOC; beyond this limit they are higher as well. This is a positive side effect of the optimization: as the 
stator current in the area of constant torque is lower than in the FOC the inverter losses will also be minimized.
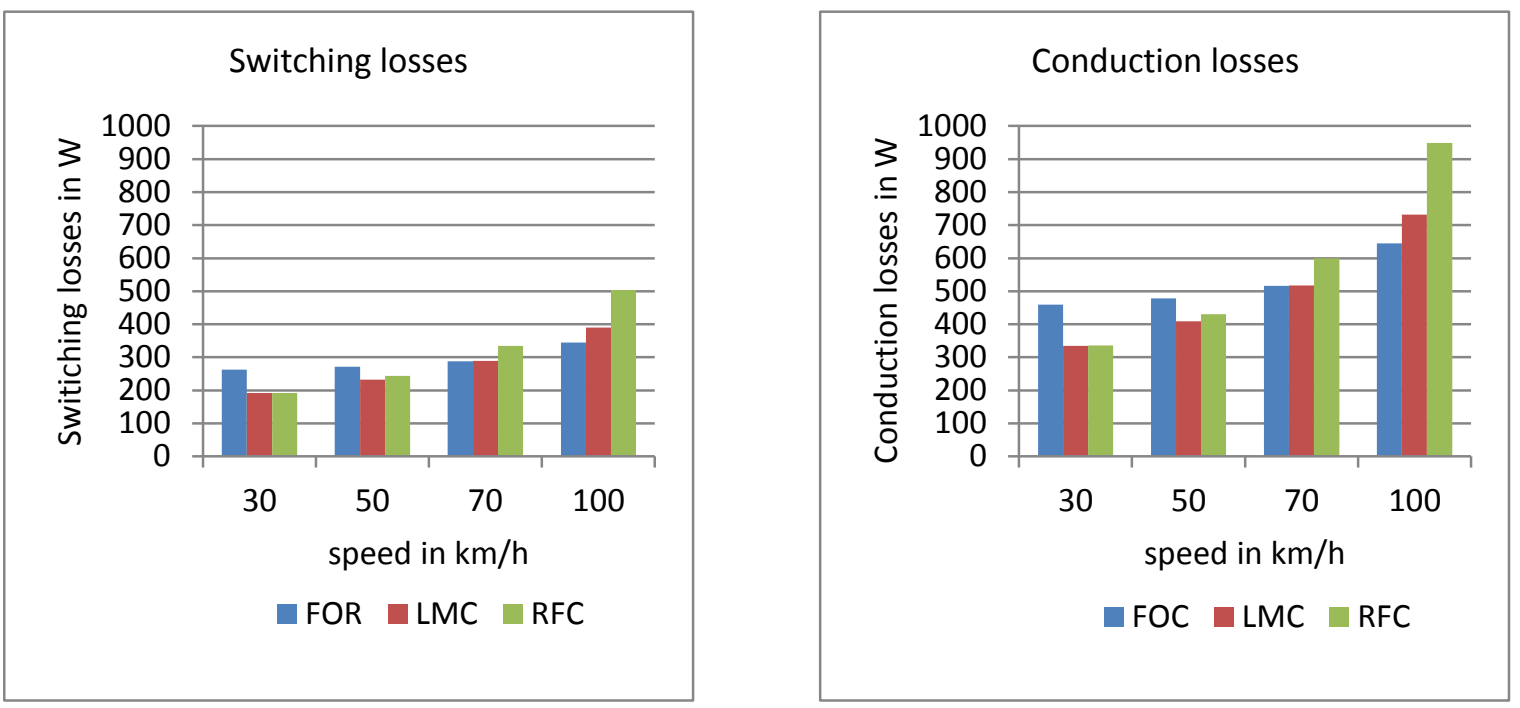

Figure 11: Switching and conduction losses at $350 \mathrm{~V}$

\subsubsection{Analysis of the Overall Efficiency}

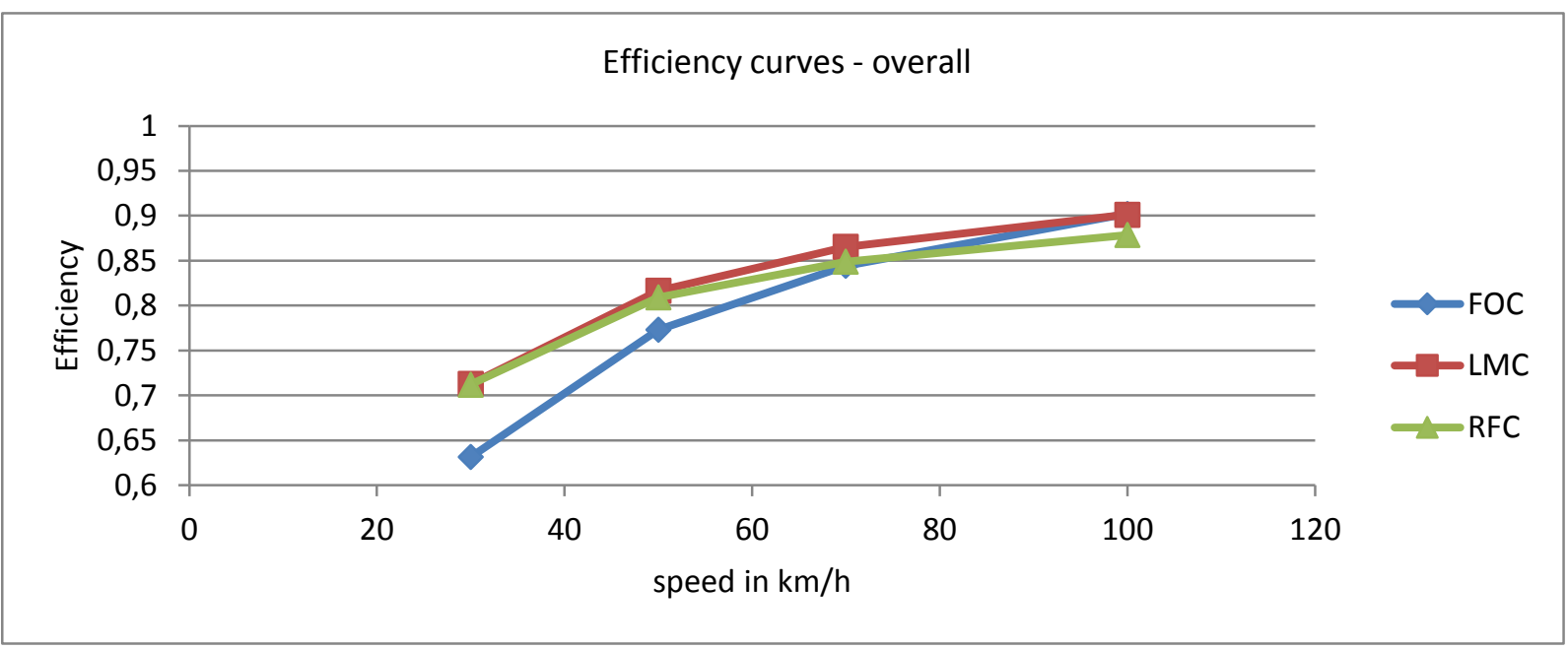

Figure 12: Efficiency curves - overall at $350 \mathrm{~V}$

Displaying the efficiency of electrical machine and inverter reveals that at any speed, LMC is more favourable for the energy balance than the FOR. With the RFC the total of the overall losses exceeds the total of the FOR from a speed of about $70 \mathrm{~km} / \mathrm{h}$.

\subsection{Loss Behavior at Varying Link Voltages}

As already mentioned in Chapter 2, the battery was modelled in such a way as to output two different link voltages: $280 \mathrm{~V}$ and $350 \mathrm{~V}$. The tests detailed in the following were each performed at these two voltages while the winding configuration in the machine remained the same. Also the reference flux values for the two voltage levels were assumed to be identical; this one flux value was determined to yield an optimum electro magnetic design.

Irrespective of the control, the copper and iron losses as well as the switching losses in the area of constant torque do not depend on the battery voltage. This is due to the fact that the components of the stator current are independent of the battery voltage and that only the fundamental wave of the induction machine was considered. Owing to this, the current ripple that is related to the link voltage and would make the iron 
losses fluctuate depending on the respective voltage will not be taken into account. Hence these losses are identical for the two voltage levels.

Merely the switching losses depend on the voltage level of the battery, due to the correlation between those of the IGBT and the diodes on the one hand and the battery voltage on the other hand.

When the machine is in the field weakening area, the three controls produce different loss behaviors that will be examined closer in the two following subchapters.

\subsubsection{Loss Behaviour in the FOC}

With field oriented control the machine is in the area of constant torque at $280 \mathrm{~V}$ up to a velocity of 70 $\mathrm{km} / \mathrm{h}$, at $350 \mathrm{~V}$ it dwells there at any velocity. This implies delayed switching from the area of constant torque to the field weakening area at $350 \mathrm{~V}$. Consequently the copper and switching losses will rise when the link voltage is lower because at $280 \mathrm{~V}$ and $100 \mathrm{~km} / \mathrm{h}$ the machine is already in the field weakening area and thus requires higher stator current due to the reduced flux. The latter is a consequence of the effort to keep the power on a constant level.

When the link voltage drops, the losses will decrease because there is already field weakening at $280 \mathrm{~V}$ and $100 \mathrm{~km} / \mathrm{h}$. At $100 \mathrm{~km} / \mathrm{h}$ the iron losses are reduced by 37,7\%; the other losses increase at a lower rate. Thus the overall losses are higher at a link voltage of $350 \mathrm{~V}$ than at $280 \mathrm{~V}$.

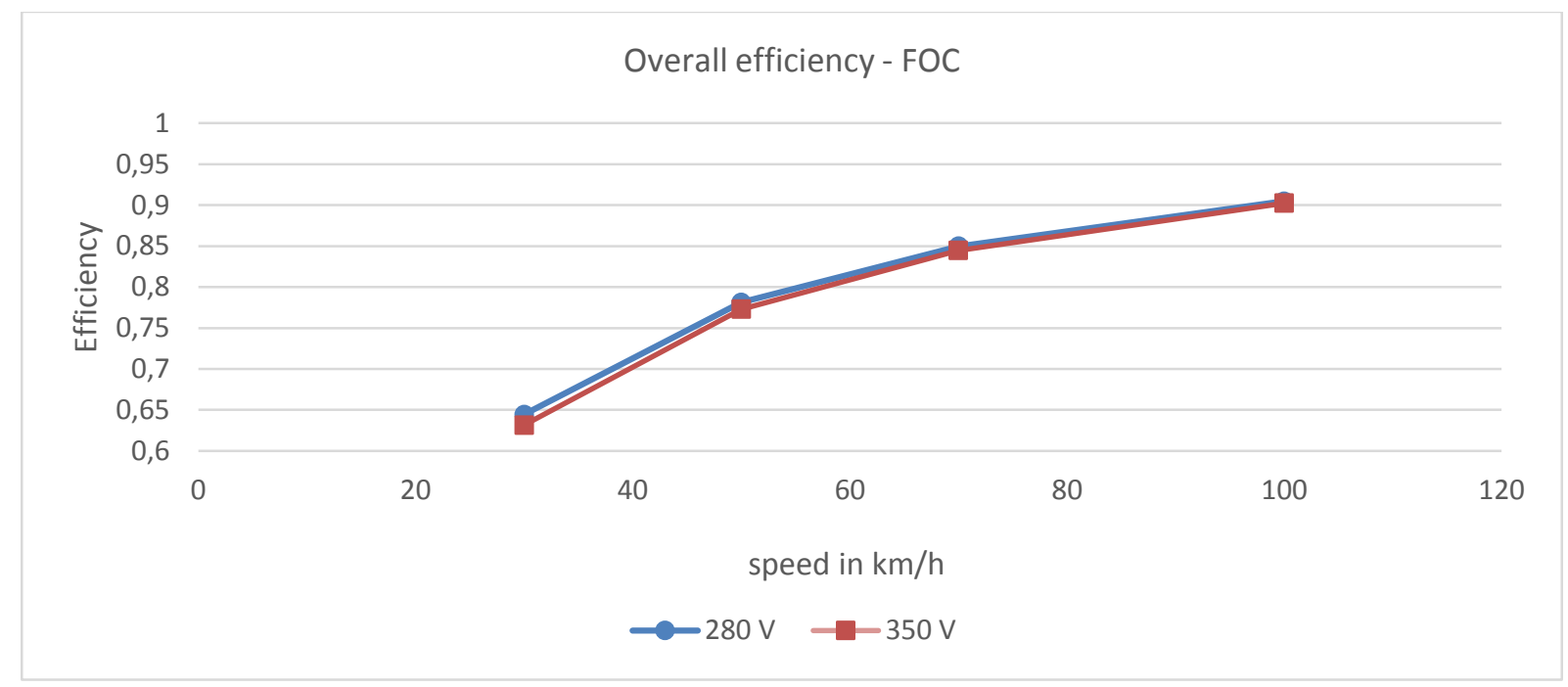

Figure 13: Overall efficiency of FOC for both voltages

\subsubsection{Loss Behaviors under RFC and LMC}

If the machine is operated by means of any of the two efficiency optimal control procedures it will remain in the area of constant torque over the entire velocity range. Thus the stator current components will always stay independent of the battery voltage. This implies that the iron and copper losses are identical for the two voltage levels. The same holds for the switching losses of the power electronics. Only these will vary because of their connection with the battery voltage and increase with a rising link voltage. Hence the efficiency at a link voltage of $280 \mathrm{~V}$ is again higher than at $350 \mathrm{~V}$. 

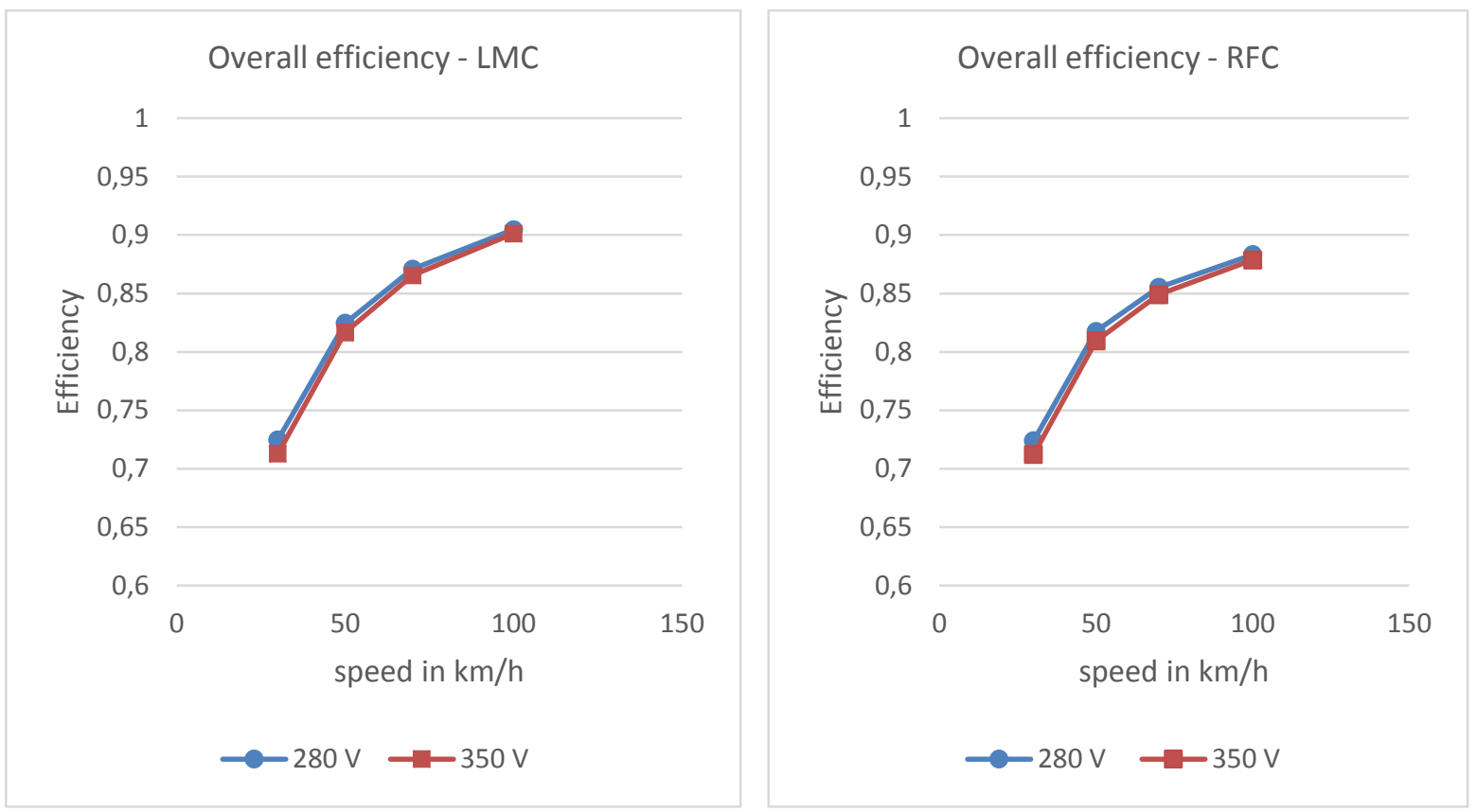

Figure 14: Overall efficiency of LMC (left) and RFC (right) for both voltages

All three controls show that the efficiencies are slightly better at $280 \mathrm{~V}$ than at $350 \mathrm{~V}$. A direct comparison between the three controls reveals that even at an open circuit voltage of $280 \mathrm{~V}$ the LMC performs better than the other two controls.

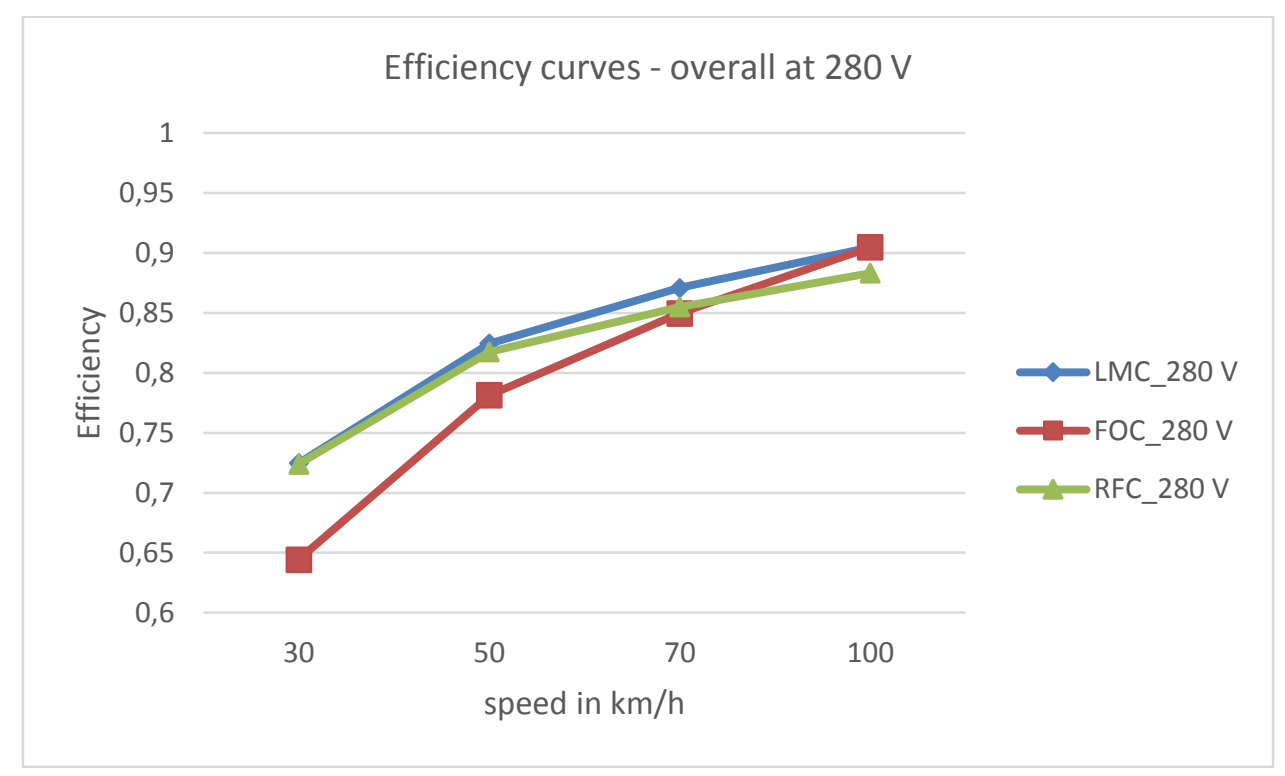

Figure 15: Efficiency curves - overall at $280 \mathrm{~V}$

\section{Conclusion}

Provided its control was selected carefully and cleverly, the induction machine can be a valuable drive for a light commercial vehicle. The results presented in [1] are confirmed. The rotor frequency optimization method (RFC) is a good choice for service in urban areas yet has some shortcomings when it comes to higher rpm. Here an LMC controlled machine is better suited that even at higher rpm has a better efficiency than does an FOC controlled one.

However, attention must be paid to an increase in rotor losses with the two efficiency optimal procedures. In this case a suitable cooling process must be employed. 
Varying link voltages produce the effect that in all three controls the efficiencies will increase in case the link voltage decreases. Both at $280 \mathrm{~V}$ and at $350 \mathrm{~V}$ the $\mathrm{LMC}$ is the control achieving the best efficiencies over the entire velocity range.

In general it can be stated that an efficiency optimal control is excellent for service within inner city speed limits and also on roads at a speed of up to $100 \mathrm{~km} / \mathrm{h}$. These are typical fields of application for a light commercial vehicle providing delivery service.

Future work will focus on determining an efficiency optimum reference flux value in the nominal range of the machine for different open circuit voltages and on repeating the tests.

\section{References}

[1] Anna-Lena Menn, Wolf-Rüdiger Canders, Markus Henke, Holistic Analytical Design of Induction Motors for Automotive Application, Ninth International Conference on Ecological Vehicles and Renewable Energies, ISBN 978-1-4799-3787-5, 2014

[2] Nasir Uddin and Sang Woo Nam, New Online Loss-Minimization-Based Control of an Induction Motor Drive, IEEE Transactions on Power Electronics, ISSN 0885-8993, Vol.23, No.2, 2008, 926-933

[3] Ali M. Bazzi, Philip T.Krein, Review of Methods for Real-time Loss Minimization in Induction Machines, IEEE Transactions on Industry Applications, ISSN 0093-9994, Vol.46, No.6, 2010, 2319-2328

[4] Ali M. Bazzi, Philip T. Krein, Comparative Evaluation of Machines for Electric and Hybrid Vehicles Based on Dynamic Operation and Loss Minimization, IEEE Energy Conversion Congress and Exposition, ISBN 978-14244-5287-3, $2010,3345-3351$

[5] Jiajia Wu, Dawei Gao, Xin Zhao, Qingchun Lu, An Efficiency Optimization Strategy of Induction Motors for Electric Vehicles, IEEE Vehicle Power und Propulsion Conference (VPPC), ISBN 978-1-424-1849-7,2008

[6] Werner Leonhard, Regelung elektrischer Antriebe, Springer-Verlag, ISBN 978-3-540-67179-4, 2000

[7] C. M. Shepherd, Design of Primary and Secondary Cells II. An Equation Describing Battery Discharge, U.S. Naval Research Laboratory, Washington, D.C., 1965

\section{Authors}
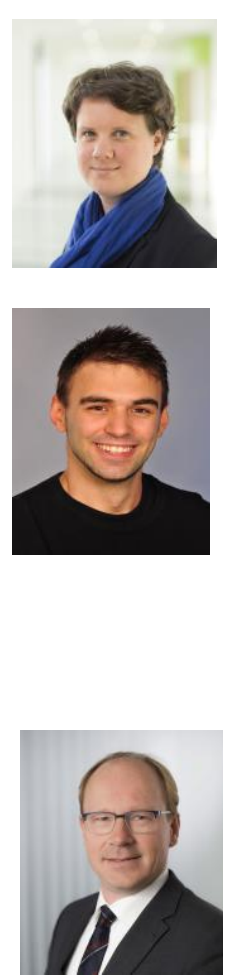

Anna-Lena Menn was born in Germany in 1985. She received the Dipl.-Ing. degree in electrical engineering from the Technical University Braunschweig in 2012. In 2012 she became a research assistant at the Institute of Electrical Machines, Tractions and Drives, Technical University of Braunschweig. Her research interests are the rating of induction motors for automotive application.

Florian Mittelstädt was born in Germany in 1989. He received his B.Sc. degree in electrical engineering from the Technical University of Braunschweig in 2014. His research interests are control of induction machines and vehicle simulation.

Markus Henke was born in Germany in 1968. He received the Dipl.-Ing. degree in electrical engineering from the University of Paderborn. In 1996 he became a research assistant at the University of Paderborn designing linear electrical machines in mechatronic railway applications. In 2002 he received his Dr.-Ing. in the field of electrical machine design and control. In 2003, he joined Volkswagen AG Wolfsburg, Germany, designing electrical machines and power electronic devices for automotive applications, where in 2007 he became head of the research department for electrical drives. Since 2012, he is University Professor for electrical drive systems and there he is the head of the Institute for Electrical Machines, Traction and Drives (IMAB). 